\title{
Fiber Bragg Grating Strain Sensing Detecting Multi-Crack Damages under Vibrating Status
}

\author{
Pei Luo \\ National Engineering Laboratory for Fiber Optic Sensing Technology, Wuhan University of Technology, Wuhan, \\ China \\ Email: zhaojx_2001@126.com
}

How to cite this paper: Luo, P. (2017) Fiber Bragg Grating Strain Sensing Detecting Multi-Crack Damages under Vibrating Status. Optics and Photonics Journal, 7, 7-13.

https://doi.org/10.4236/opj.2017.78B002

Received: March 20, 2017

Accepted: August 7, 2017

Published: August 10, 2017

\begin{abstract}
The multi-crack damages modal of simple supported beam has been build, at the vibrating status, the multi-damage detecting method of simple supported beam measured by fiber Bragg grating strain sensing array has been studied. From $0 \mathrm{hz}$ to $200 \mathrm{hz}$, using exciter vibrating simple supported beam, with different damages, resonant frequency of simple supported beam has changed. So, when the damage appears in simple supported beam, the local rigidity will decrease, the resonant frequency of simple supported beam will be affected, the damage status of simple supported beam have been determined by this. The experimental result indicates that the resonant frequency of simple supported beam has changed when there is no damage, one damage, two damages, three damages on simple supported beam. According to this, the fiber Bragg grating strain sensing array can detect multi-crack damage of simple supported beam under vibrating status.
\end{abstract}

\section{Keywords}

Vibration, Fiber Bragg Grating Strain Sensing Array,

Simple Supported Beam, Damage Detection, Resonant Frequency

\section{Introduction}

The crack existing in structure will decrease the local rigidity, and descend of the local rigidity closely relates to change of the resonant frequency. In actual engineering, the disastrous accident often occurs because the tiny crack exists and expands in structure. The beam structure is the main component in actual engineering, is the basic component forming different structures, and also is the common flexural component in engineering application, it has been applied in the engineering field, such as mechanical, traffic, and architecture. At present, 
many detection methods have obtained good results on the crack detecting technology, such as ultrasonic, $\mathrm{x}$-ray, acoustic emission, liquid penetration coloring, combined flaw detection, magnetic powder, turbulence, microwave, but these methods mainly fit to detect defects of static equipment, they cannot quantitatively analyze the on-line equipment.

Amount of research has been studied on detecting crack by researchers at home and abroad, S. Caddemi [1] et al. have studied the non-linear dynamic response of the Euler-Bemoulli beam with switching cracks. A. Khorram [2] et al. have studied Mutiple cracks detection in a beam subjected to a moving load, Li Yiqian [3] et al. have studied the damage sensitivity of dynamic properties of cantilever beam, Tang Tianguo [4] et al. have studied strain energy method for analysis of beams with crack damage, Li Jian [5] et al. have simulated and analyzed modal frequency change regulations of the damage simple supported beams using finite element soft, Jiang Haibo [6] et al. have studied vibration mode analysis of simple supported beam with damage boundary condition, $\mathrm{Xu}$ Ping [7] has studied modal curvature characteristics of a simple supported beam with a local crack, An Yonghui [8] et al. have simulated and analyzed the damage severity identification of simple supported beam bridges, these researches have studied damage beam from all aspects, but these researches all use electric sensors, they cannot carry on long distance on-line monitoring.

Fiber Bragg grating sensing technology is a new technology, it has many advantages, such as small structure, convenient to use, immune to electromagnetic, easily forming network, transmission distance, fit to on-line monitoring. In recent years, fiber Bragg grating sensing technology has been widely applied at home and abroad, industrialization of grating has promoted development of fiber Bragg grating sensing technology, various fiber Bragg grating sensors have been studied, these sensors have been widely applied in the monitoring locale, and they are developing function of real-time monitoring. In this paper, Fiber Bragg grating strain sensing array has been applied to measure vibration of simple supported beam, using the vibrating data to analyze the dynamic response of simple supported beam, and the real-time dynamic monitoring of simple supported beam will be realized.

\section{Free Vibration Analysis of Simple Supported Beam}

To study cracks affecting vibration characteristic of simple supported beam, the vibration mechanics model of intact beam and crack beam must be found at first, the influence rule of beam vibration which crack caused will be discussed through studying vibration characteristics of beam at different status.

According to structural dynamics theory, equation of structural free vibration can be shown as below:

$$
[M]\{\ddot{x}\}+[C]\{\dot{x}\}+[K]\{x\}=\{0\}
$$

And the characteristic equation can be shown as below: 


$$
\left([K]-\omega^{2}[M]\right)[\varphi]=[0]
$$

According to Equation (2), natural frequency of structure is relate to quality and stiffness of structure, so, when structure has any damage, the quality and stiffness of structure will change. And the two changes must cause structural natural frequency and vibration mode being changed, then, due to Equation (2), we can obtain the characteristic equation after structure has damage:

$$
\left(([K]+[\Delta K])-\left(\omega^{2}+\Delta \omega^{2}\right)([M]+[\Delta M])\right)([\phi]+[\Delta \phi])=[0]
$$

In the damage crack structure, mass of structure change little, and can be ignored, so, the equation can be written as:

$$
\left(([K]+[\Delta K])-\left(\omega^{2}+\Delta \omega^{2}\right)([M])\right)([\phi]+[\Delta \phi])=[0]
$$

Spreading Equation (4), ignores quadratic term of frequency, variation of natural frequency is:

$$
\Delta \omega^{2}=\frac{[\phi]^{T}[\Delta K][\phi]}{[\phi]^{T}[M][\phi]}
$$

To vibration mode $\left[\phi_{i}\right]$ of I order,

$$
\Delta \omega_{i}^{2}=\frac{\left[\phi_{i}\right]^{T}[\Delta K]\left[\phi_{i}\right]}{\left[\phi_{i}\right]^{T}[M]\left[\phi_{i}\right]}
$$

Equation (6) is frequency damage equation. If structure is damaged, stiffness change of J unit is $\left[\Delta K_{j}\right]$, and Equation (6) can be changed as:

$$
\Delta \omega_{i}^{2}=\frac{\left[\phi_{i}\right]^{T}\left[\Delta K_{j}\right]\left[\phi_{i}\right]}{\left[\phi_{i}\right]^{T}[M]\left[\phi_{i}\right]}
$$

Suppose change of characteristic value can be expressed as function of damage position and damage degree, that is:

$$
\Delta \omega_{i}^{2}=\Delta \omega_{i}^{2}\left(\beta_{j}, j\right)
$$

$\beta_{j}$ is a quantity scarlar, it expresses as damage degree of J unit, the following formula exists:

$$
\left[\Delta K_{j}\right]=\beta_{j}\left[K_{j}\right]
$$

Substituting Equation (9) to Equation (7), it can obtain:

$$
\Delta \omega_{i}^{2}=\frac{\beta_{j}\left[\phi_{i}\right]^{T}\left[K_{j}\right]\left[\phi_{i}\right]}{\left[\phi_{i}\right]^{T}[M]\left[\phi_{i}\right]}
$$

According to Equation (10), frequency change of simple supported beam relies on not only damage position but also damage degree. So, each order natural frequency of simple supported beam can be obtained by free vibration equation of simple supported beam, and different crack length has different effect to stiffness of beam. As element stiffness decreasing, each order natural frequency of 
simple supported beam will drop off; when unit stiffness of symmetric position decrease the same amplitude, natural frequency changes the same, when different position damage makes a difference because of damage degree, the change value of frequency will be different. When unit stiffness decrease less, each order natural frequency of crack simple supported beam change little, when unit stiffness of simple supported beam decrease exceed fifty percent or even greater, natural frequency of simple supported beam will decrease more.

\section{Building Experimental Installation and Collecting with Analyzing Experimental Results That Fiber Bragg Grating Strain Sensing Array Detecting Damage of Simple Supported Beam}

\subsection{Experimental Installation Building}

Vibration experiment is carried on simple supported beam, basic situation is the following: length of beam is $500 \mathrm{~mm}$, width of beam is $70 \mathrm{~mm}$, height of beam is $2 \mathrm{~mm}$, position of exciter is $250 \mathrm{~mm}$ away from non-crack tip of beam. Four pieces of stainless steel plate have been fabricated, each steel plate delegates a situation, that is: no damage, one crack, two cracks, three cracks; fifteen gratings are pasted on each steel plate, as is shown in the Figure 1.

The paste length of fiber grating is $20 \mathrm{~mm}$, the head-end of the first grating is $40 \mathrm{~mm}$ away from fixed end of beam, the terminal of the first grating is $80 \mathrm{~mm}$ away from the head-den of the second grating, the rest can be done in the same manner, the terminal of the fifth grating is $40 \mathrm{~mm}$ away from other fixed end of beam; because fifteen gratings are divided three groups pasted on surface of beam, so vertical paste states of the other two groups of gratings agree with the first group. Horizontal paste states are: the first group is $15 \mathrm{~mm}$ away from horizontal side of beam, the second group pastes on axis of beam, the third group symmetric pastes on other side of beam.

Fifteen Bragg gratings are fiber Bragg gratings array which connected to an

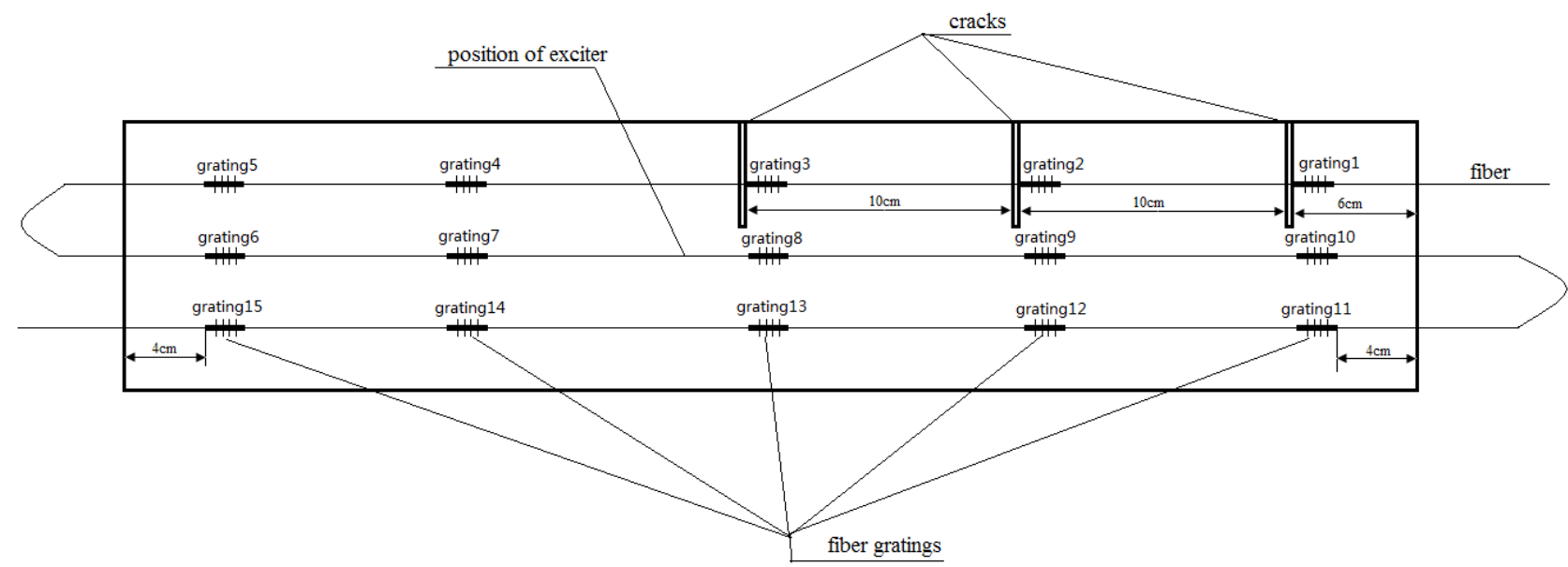

Figure 1. Graph of fiber Bragg gratings distribution. 
optical fiber, these gratings divided three groups paste on surface of beam, before pasted, surface of beam must be handled, after cleaned by alcohol, marks are made on position which need paste fiber gratings, and then, fiber Bragg gratings are pasted accurately. After pasted by epoxy-resin glue, the steel plate must be placed quietly 24 hours, and the vibration test can be done. Before collecting the experimental data, preloading on beam, that is: vibrating beam at acceptable range, and each Bragg grating is in working condition.

Before doing experiments, the experimental equipment must be preheated half an hour, in this experiment, the following equipment must be used: exciter, signal generator, power amplifier, fiber grating demodulator and computer. Experimental processing Figure 2.

\subsection{Experimental Results Analyzing}

The experimental process of fiber Bragg grating sensing array detecting damage of simple supported beam is the following: in the range of $0-200 \mathrm{hz}$, the output voltage of signal generator is kept constancy; exciting simple supported beam in turn, during vibrating, we find that the collected signals of sensors are standard sine signal from $10 \mathrm{hz}$ to $30 \mathrm{hz}$; when the exciting frequency is greater than 30 $\mathrm{hz}$, the wave form of sensor has changed, and there are some harmonic waves attaching on sine wave. When beam is in resonance state, the wave form of undamaged beam by sensor detecting is sine signal; when there are some damages in beam, the wave form of damaged beam by sensor detecting will change a little, there are many harmonic waves on the sine wave, it is because beam resonating, two end faces of crack cause to collide with each other, then nonlinear signal appear in signal of sensor. The collected signals of sensor in resonance state are the following Figures 3-6.

\section{Conclusion}

We can obtain the following conclusion by studying and analyzing, fiber Bragg grating sensing array can detect damage of each position of simple supported beam. According to vibration analysis of $0-200 \mathrm{hz}$, when simple supported beam is damaged, natural frequency of simple supported beam will change, and the vibrating wave form changes also. So, it can be confirmed that simple supported beam is injured or not according to change of natural frequency. It is ob-

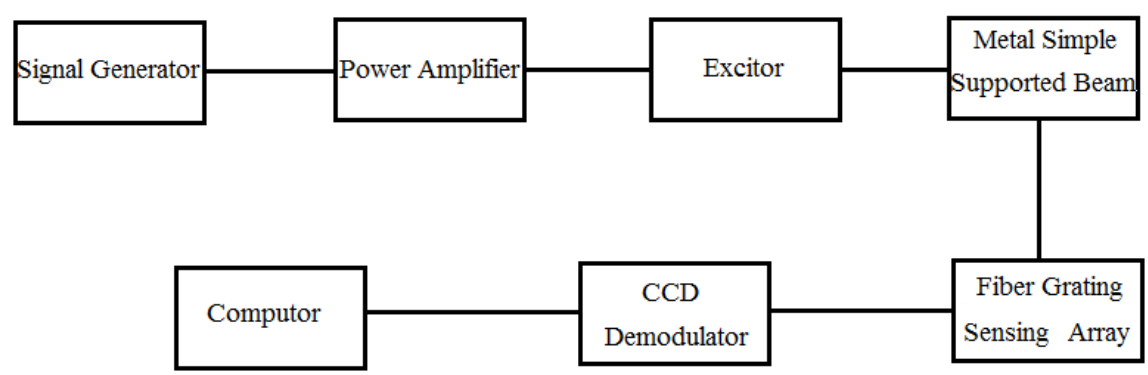

Figure 2. Experimental processing figure. 


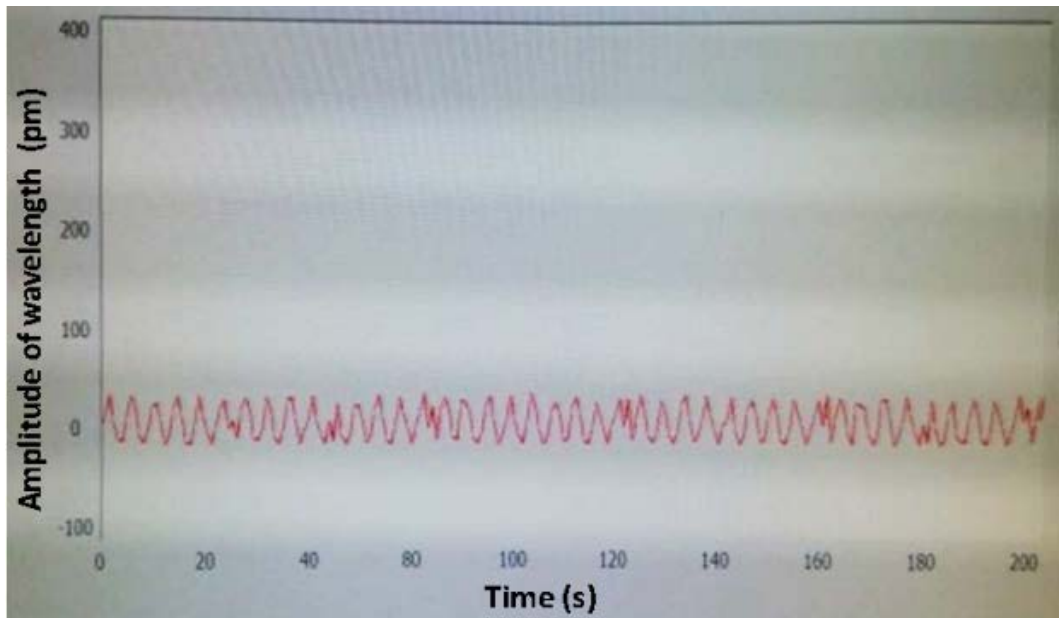

Figure 3. The resonance wave form of undamaged beam.

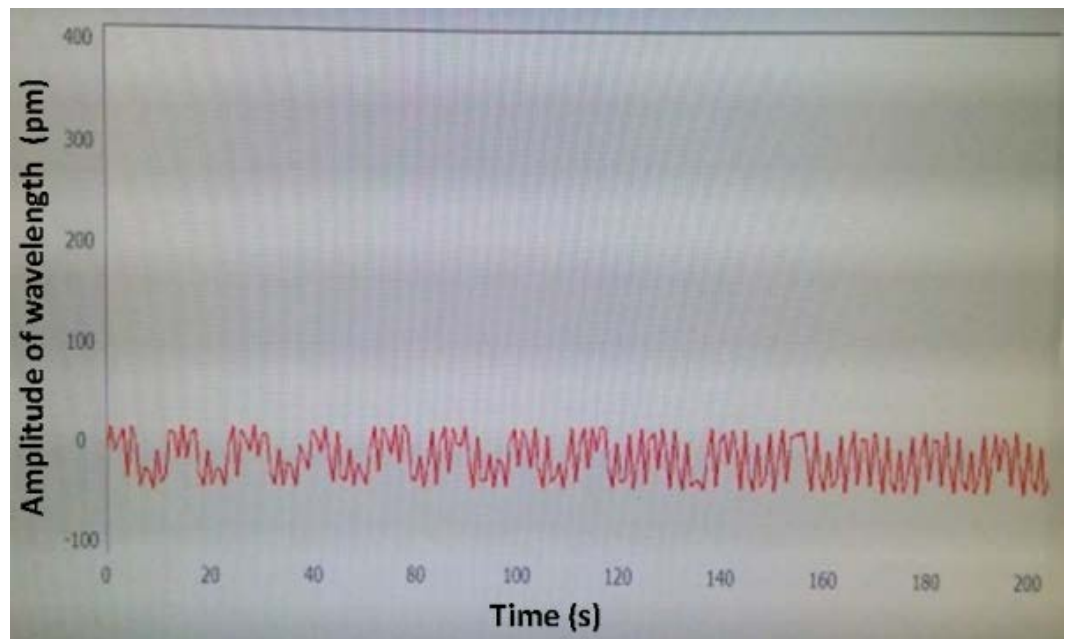

Figure 4. The resonance wave form of one crack beam.

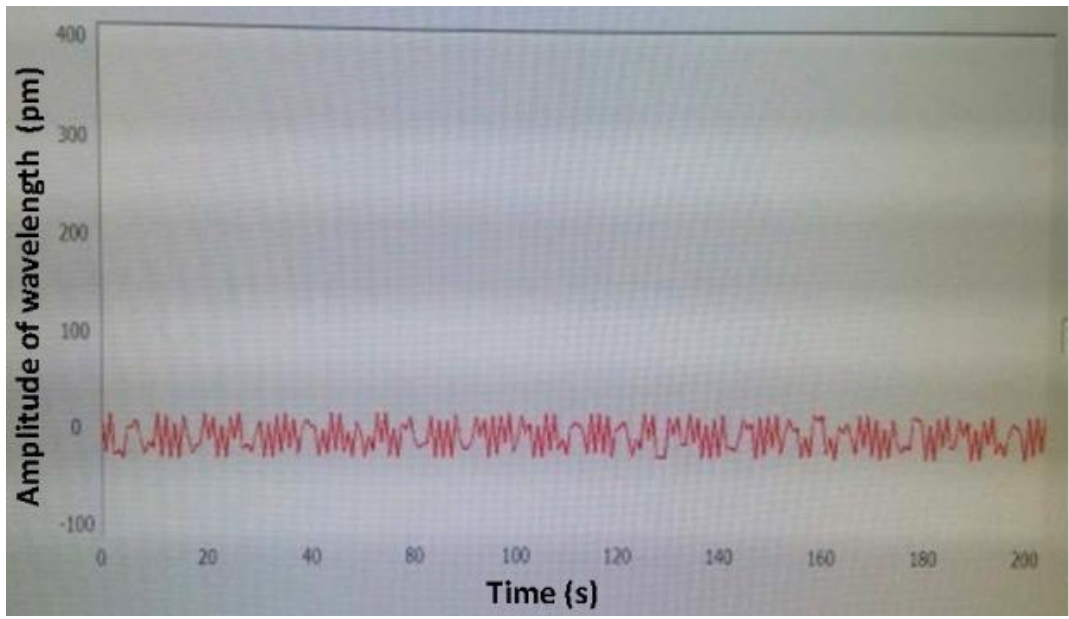

Figure 5. The resonance wave form of two cracks beam.

vious that fiber Bragg grating sensing array can detect damage of structure in 


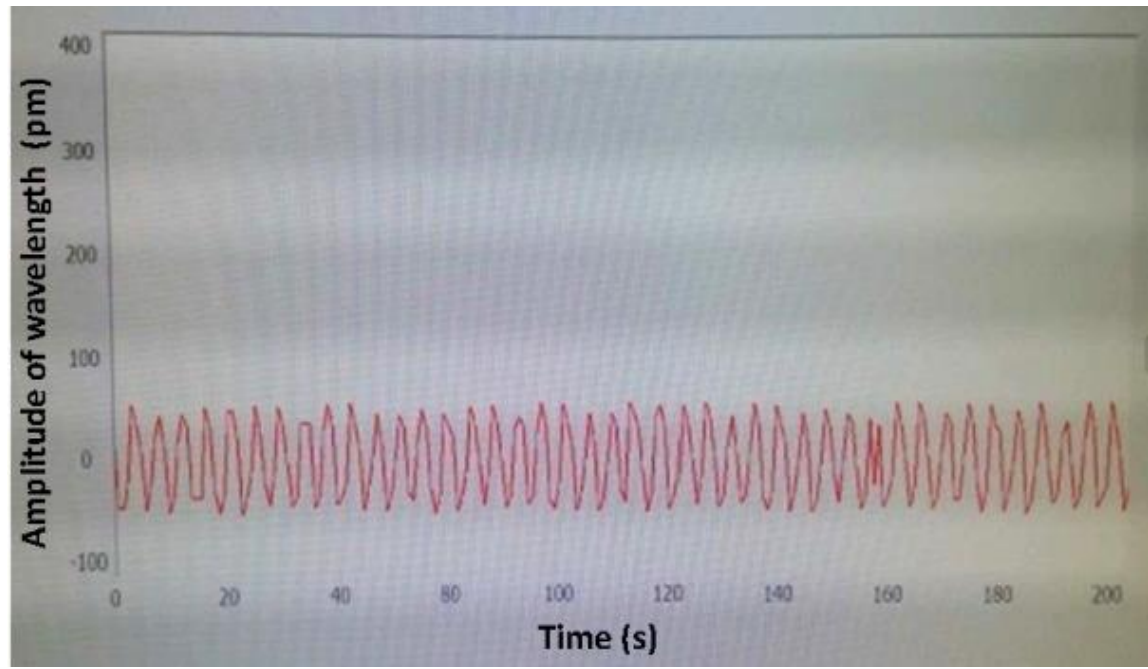

Figure 6. The resonance wave form of three cracks beam.

vibrating status.

\section{Acknowledgements}

This research was financially supported by the national science foundation (51308428) and the high and new technology special project of Hubei Province.

\section{References}

[1] Caddemi, S., Calio, I. and Marletta, M. (2010) The Non-Linear Dynamic Response of the Euler-Bernoulli Beam with an Arbitrary Number of Switching Cracks. International Journal of Non-Linear Mechanics, 45, 714-726. https://doi.org/10.1016/j.ijnonlinmec.2010.05.001

[2] Khorram, A., Rezaeian, M. and Bakhtiari-Nejad, F. (2013) Multiple Cracks Detection in a Beam Subjected to a Moving Load Using Wavelet Analysis Combined with Factorial Design. European Journal of Mechanics A/Solids, 40, 97-113. https://doi.org/10.1016/j.euromechsol.2012.12.012

[3] Li, Y.Q., Xiang, Z.H. and Cen, Z.Z. (2009) Study on the Damage Sensitivity of Dynamic Properties of Cantilever Beams. Engineering Mechanics, 26, 17-23.

[4] Tang, T.G., Liu, H.W., Chen, C.H. and Liu, X.S. (2005) Strain Energy Method for Analysis of Beams with Crack Damage and Experimental Study. Engineering $\mathrm{Me}$ chanics, 22, 39-45.

[5] Li, J., Xue, G. and Li, F.G. (2009) Finite Element Analysis on Modal Frequency Change Regulations of the Damage Simple Supported Beams. Journal of Inner Mongolia University of Science and Technology, 28, 350-353.

[6] Jiang, H.B. and Zhao, R.D. (2004) Vibration Mode Analysis of Simply Supported Beam with Damage Boundary Condition. Journal of Vibration and Shock, 23, 7276.

[7] Xu, P. (2011) Modal Curvature Characteristics of a Simple Beam with a Local Damaged Crack. Chinese Journal of Solid Mechanics, 32, 717-715.

[8] An, Y.H. and Ou, J.P. (2013) Experimental and Numerical Studies on Damage Severity Identification of Simply Supported Beam Bridges. Journal of Vibration, Measurement \& Diagnosis, 33, 60-66. 
Submit or recommend next manuscript to SCIRP and we will provide best service for you:

Accepting pre-submission inquiries through Email, Facebook, LinkedIn, Twitter, etc. A wide selection of journals (inclusive of 9 subjects, more than 200 journals)

Providing 24-hour high-quality service

User-friendly online submission system

Fair and swift peer-review system

Efficient typesetting and proofreading procedure

Display of the result of downloads and visits, as well as the number of cited articles Maximum dissemination of your research work

Submit your manuscript at: http://papersubmission.scirp.org/

Or contactopj@scirp.org 